The authority of Scriptures in the Work of John Locke:

the problem of the proof of traditional revelation

\title{
La autoridad de las Escrituras en la obra de Jobn Locke: el problema de la prueba de la revelación tradicional
}

\author{
Dr. Joan Severo Chumbita \\ Universidad de Buenos Aires \\ Consejo Nacional de Investigaciones Científicas y Técnicas \\ joanchumbita@gmail.com \\ DOI: http://dx.doi.org/10.15366/bp2018.18.005 \\ Bajo Palabra. II Época. No18. Pgs: 99-114
}

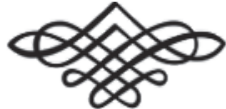


Recibido: 03/03/2017

Aprobado: 29/07/2018

\section{Resumen}

En el presente artículo se estudiará el modo en que se sustenta la autoridad de la revelación de las Escrituras en la obra de John Locke. En primer lugar, se establecerá la asiduidad y centralidad de la referencia a las Escrituras como fuente de autoridad moral. En segundo lugar, se analizará la articulación propuesta entre revelación y razón. Por último, se considerará la coherencia entre la vigencia del empirismo racionalista de la epistemología lockeana y la acepción de una prueba no demostrativa por vía empírico-racional de la revelación, que se basa en la procedencia divina validada por la existencia de los milagros.

Palabras clave: Locke, razón, fe, Escrituras, latitudinarismo, escepticismo.

\section{Abstract}

In this paper we will study the way in which Scriptural revelation authority is sustained in the work of John Locke. First, we will show the recurrence and centrality of the Scriptural reference as a source of moral authority. Second, we will analyze the articulation proposed between revelation and reason. Finally, we will consider the coherence between the validity of rationalistic empiricism in the Lockean epistemology and the acceptation of a revelation's undemonstrative proof in an empiric-rational way, supported on the divine provenance validated by the existence of miracles.

Keywords: Locke, Reason, faith, Scriptures, Latitudinarianism, Skepticism. 
$\mathrm{L}$

o primero que hay que destacar es que las Escrituras constituyen una fuente de referencia permanente en la obra de Locke. En efecto, tanto para la reconstrucción de la condición originaria del hombre a partir del Génesis como para establecer los principios de la moralidad y corroborar la ley de naturaleza, Locke recurre a las Escrituras. Si en Two Treatises of Government, I (TT, I) se reinterpretará el Génesis para desestimar el dominio privado y político de Adán y sus herederos sobre el género humano que sostuviera Filmer (TT, I, \$23-25, $\$ 27)$, en The Reasonableness of Christianity $(R)^{1}$ se apelará a la autoridad de los Evangelios para establecer los principios morales de un modo no demostrativo. En base a esta recurrencia a las Escrituras en argumentaciones fundamentales de la obra lockeana, se ha criticado la lectura hobbesiana y secular de Strauss (Strauss, 1992: 165, 202, 219-227; Yolton, 1958: 481-492; Dunn, 1969: 187188, 193, 199; véase también 100-101; IX, XI, 5, 9, 158, 169; Simmons, 1992: $12,15,68)$

Sin embargo, a pesar del acierto de muchas de estas críticas, veremos que la apelación a las Escrituras no supone una asunción in toto de su autoridad. Comencemos, por tanto, por presentar la validación del relato bíblico de los Evangelios sobre la figura de Jesús como hijo de Dios, para establecer la primacía de su autoridad frente a la tradición filosófica en materia moral. Según Locke, Jesús:

[...] declaró a toda la humanidad que quien quiera que crea que él es el Salvador prometido y le acepte ahora resucitado de entre los muertos y constituido Señor y Juez de todos los hombres para ser su Rey y Soberano, sería salvado. Esta es una proposición sencilla e inteligible; el Dios misericordioso parece con esto haber tenido en cuenta a los pobres de este mundo y a la masa de la humanidad. [...] Los escritores y polemistas en materia de religión la llenan de sutilezas y la adornan con ideas que hacen partes necesarias y fundamentales de ella, como si no hubiera otro camino hacia la iglesia sino a través de la Academia o del Liceo. La mayoría de la humanidad no tiene tiempo libre para el saber y la lógica y las distinciones sutiles de las escuelas $(R, 1977: 248-249$, véase también 227, 229).

Este pasaje permite advertir que, a diferencia de Essays on the Law of Nature $(E L N)^{2}$, la referencia a la autoridad moral de las Escrituras se realiza aquí en contra-

\footnotetext{
${ }^{1}$ Usaremos en todos los casos la edición castellana, traducida por Leandro González Puertas.

2 Usaremos en todos los casos la edición castellana, traducida por Carlos Mellizo.
} 
posición a la tradición filosófica. Si bien en la filosofía antigua podemos hallar los principios morales, lo cual habla del carácter universal de las leyes de naturaleza, su moralidad resulta ineficaz en comparación con la del cristianismo (Ashcraft, 1969: 219). En este sentido, Locke subraya la "oscuridad e ignorancia del Dios verdadero, el vicio y la superstición" en que vivía la mayoría de los hombres con anterioridad a la llegada del Mesías ( $R$, 1977: 216-217). Si en ELN y Essay Concerning Human Understanding $\left(E_{\text {ssay }}\right)^{3}$ se destacaba el carácter cognoscible de la ley de naturaleza, así como su posibilidad de demostración no menos certera que el de la geometría (Essay, IV, III, \$1; véase también IV, III, \$18; IV, IV, \$6; I, IV, \$1, \$4; IV, V, \$11, IV, XII, \$8; ELN, 2007: 26-28; EMO4, 1991b: 93; Gough, 1964: 7), aquí la moral es tanto más eficaz no cuanto mejor es conocida racionalmente, sino en cuanto mayor sea su impacto social.

Se trata antes de un desplazamiento que de una contradicción. En efecto, surge antes de incorporar el criterio utilitarista de las consecuencias, el cual relativiza la importancia del conocimiento en materia moral, antes que de una negación de la posibilidad del conocimiento moral o un rechazo completo de su valor ${ }^{5}$. Locke reconoce aún a los antiguos el saber acerca de la ley de naturaleza, e incluso sobre el Dios único, pero lo hace con una importante salvedad: "si le reconocían y le adoraban, era sólo en sus mentes" ( $R, 1977: 217)$. La deficiencia moral de los filósofos antiguos respecto al cristianismo no radica fundamentalmente en el orden del saber, pues "la razón, como siempre, hablando tan claramente a los sabios y virtuosos", era perfectamente comprendida por ellos $(R, 1977: 217)$. De hecho, Locke considera la posibilidad de que todos los principios morales del cristianismo pudieran haber sido conocidos por los antiguos. Sin embargo, aún si fuera este el caso, ello no impediría la necesidad práctica del cristianismo:

\footnotetext{
${ }^{3}$ Usaremos en todos los casos la edición castellana, traducida por Carlos Mellizo.

${ }^{4}$ An Examination of P. Malebranche's Opinion of Seeing All Things in God.Usaremos en todos los casos la edición castellana, traducida por José Antonio Robles y Carmen Silva.

${ }^{5}$ En un breve texto titulado Of Ethic in General $(E G)$, Locke presenta claramente el consecuencialismo moral: "Las acciones morales son sólo aquellas que dependen de la elección de un agente libre y con entendimiento. Y un agente libre y con entendimiento busca naturalmente aquello que causa placer y rehuye aquello que causa dolor; i. e. naturalmente busca la felicidad y escapa de la desdicha. [ ] si la felicidad y la desdicha consisten sólo en el placer y el dolor [ ] bien y mal, siendo términos relativos, no denotan nada en la naturaleza de la cosa, sino sólo la relación que mantiene con otro, en su inclinación y su tendencia a producir placer o dolor; y así vemos y decimos que lo que es bueno para un hombre es malo para otro" (EG, 2011: 159-160; véase también Essay, II, XXVIII \$5). De aquí que en Essay se identifique directamente bondad con placer: "Las cosas, por lo tanto, son buenas o malas solamente en relación al placer y al dolor” (Locke, Essay, II, XX, \$2; véase también II, XXVIII \$5; Hall, 1981: 61; Gaela Esperanza, 2006: 73). Esta misma definición la encontramos en Ethics in General (De la ética en General): "Así, lo que causa el mayor placer es el mayor bien, y lo que causa el mayor dolor es el mayor mal. [ ] la felicidad y la desdicha consisten sólo en el placer y el dolor, ya sea de la mente o del cuerpo, o de ambos" (EG, 2011: 159). El consecuencialismo moral se traduce en TT, II, \$34, 51, en integración entre mandato divino y conveniencia particular.
} 
Aún si alguno pensara que, de los dichos de los sabios paganos antes del tiempo de nuestro Salvador, se podía hacer una colección de todas aquellas reglas de la moralidad que se encuentran en la religión cristiana, sin embargo, esto no impediría en absoluto que el mundo, no obstante, tuviera tanta necesidad de nuestro Salvador y de la moralidad pronunciada por él. Admítase (aunque no es verdad) que antes todos los preceptos morales del Evangelio eran conocidos por unos u otros entre la humanidad. Sin embargo, no se considera dónde, ni cómo ni con qué utilidad ( $R$, 1977: 224-225; véase también 228).

Si bien Locke no reconoce el pleno conocimiento de la ley de naturaleza a los antiguos, sí les reconoce la posibilidad de acceder a tal conocimiento, como lo requiere el alcance universal de la ley de naturaleza y la razón $\left(R, 1977: 227^{6}\right)$. La diferencia fundamental con el cristianismo radica en la capacidad de utilizar el saber moral para transformar la sociedad. Las obras de Zenón, Epicuro y Séneca, dan cuenta de la capacidad de la razón individual de descubrir la ley de naturaleza. Sin embargo, "vemos el poco éxito que tenían los filósofos antes del tiempo de nuestro Salvador" ( $R, 1977: 223)$. El criterio que Locke introduce aquí, que no se hallaba en $E L N$, es el de la utilidad para el mayor número (ELN, 2007: 95-96, 98, 102-103; véase también TT, II, \$180; Singh, 1961: 112; Gough, 1964: 6, 16; Simmons, 1992: 39). En este sentido, en el registro de las consecuencias prácticas, el conocimiento de los filósofos "nunca tuvo bastante autoridad para influir en la muchedumbre" $\left(R, 1977: 217^{7}\right)$. Los antiguos hablaban sólo para "unos pocos que tenían mucho ocio, mejores conocimientos y estaban acostumbrados al razonamiento abstracto" ( $R, 1977: 234)$. Contra esta moral aristocrática, Locke reivindica el lenguaje llano del cristianismo ( $R$, 1977: 229-230, 233-234). En efecto, a fin de transformar a las masas, que debe ser el objeto de la ética, las sutilezas teóricas no tienen la menor utilidad: "Si Dios hubiera tenido intención de que ninguno que no fuese el escriba sabio, el polemista o los sabios de este mundo fueran cristianos y se salvasen, la religión hubiera sido así preparada para ellos, llena de teorías y sutilezas, términos oscuros e ideas abstractas" ( $R, 1977: 250)$.

Sin embargo, como hemos mencionado, el avance que representa el cristianismo no se debe solamente a la aplicación de un saber ya establecido. El Nuevo Testamento trae consigo elementos de una moral más elevada. Locke destaca el recono-

\footnotetext{
6 "No es suficiente que por todas partes estuvieran esparcidos los dichos de los sabios conformes a la recta razón. La ley de naturaleza es también la ley de la conveniencia; y no es sorprendente que aquellos hombres habilidosos y estudiosos de la virtud (que tenían ocasión de pensar en una parte particular de ella) llegasen, por la meditación, a lo justo aun desde su conveniencia y hermosura observables sin descubrir la obligación de los verdaderos principios de la ley de naturaleza y los fundamentos de la moralidad" ( $R, 1977: 227)$.

7 La única excepción en la antigüedad la constituye para Locke el pueblo judío, el cual, reafirmando así la autoridad de las Escrituras, más precisamente del Antiguo Testamento, había constituido un Estado que hacía de la “creencia y adoración de un solo Dios" "la religión nacional” $(R, 1977: 217)$.
} 
cimiento de la sacralidad de toda vida humana como propiedad divina (TT, II, \$6). En este sentido, el Nuevo Testamento supera a la moral de "filósofos, estudiosos y pensadores", quienes no condenaron el derecho de los padres sobre la vida de los hijos: "ni aun habrían podido convencer a la parte civilizada del mundo de que ellos no habían dado las vidas a sus hijos y no podían, sin delito, quitárselas" $(R, 1977$ : 230; TT, II, \$135). Los antiguos no poseían una moral acabada, a pesar de haber descubierto gran parte de las leyes de naturaleza. Los sacerdotes no se ocupaban suficientemente de la virtud, los filósofos no referían adecuadamente a Dios, y ambos, con toda su erudición, poseían una moral inferior a la de los apóstoles ignorantes de Jesús $\left(R, 1977: 224-225^{8} ; 230-231\right)$.

Por último, Locke le reprocha a la filosofía el fracaso en su propio terreno, esto es, no haber sido capaz de demostrar las verdades morales del mismo modo que se han demostrado las verdades matemáticas $(R, 1977: 233$; véase también 229-230; Gough, 1964: 7; Hancey, 1976: 443'). Careciendo de demostración suficiente, la moral no puede apelar sino a la acreditada autoridad divina. Locke considera, en efecto, que la moralidad no puede establecerse sino por una de estas dos vías. En este sentido, el cristianismo suple la deficiencia demostrativa de la filosofía.

Aquel a quien alguien pretenda establecer así y tener sus reglas como lecciones auténticas, ha de demostrar que, o constituye su doctrina en principios de la razón evidentes en sí mismos y de esto deduce todas sus partes, por manifestación clara y evidente, o debe mostrar su patente de los cielos, que viene con autoridad de Dios para pronunciar la voluntad y mandamientos al mundo. De la manera anterior nadie que yo sepa, antes del tiempo de nuestro Salvador, jamás nos dio o intentó darnos una moralidad $(R, 1977: 227$ - 228).

Se sigue de lo dicho hasta aquí que Locke asume en $R$ la veracidad histórica y la autoridad moral del Nuevo Testamento (Ashcraft, 1968: 900). En TT, I, esta apelación resulta aún más explícita en cuanto a identificar en la palabra escrita el testimonio de la palabra de Dios: "En vuestras manos son entregados, dice Dios a Noé y sus hijos [...]" (TT, I, \$39). "Todas las cosas movientes que viven -dice Dios- serán alimento para ti; lo cual no le fue permitido a Adán en su privilegio" (TT, I, \$39). En esta misma dirección, Locke considera en Essay a las Escrituras como autoridad infalible junto a la razón: "Pero en semejantes casos también tenemos la razón y la Escritura, dos reglas infalibles, para saber si se trata o no de iluminaciones divinas"

\footnotetext{
8 "[...] el que recoja todas las reglas morales de los filósofos y las compare con aquellas contenidas en el Nuevo Testamento, hallará que no igualan a la moralidad predicada por nuestro Salvador y enseñada por sus apóstoles, un colegio compuesto en su mayoría de pescadores ignorantes, pero inspirados" ( $R, 1977: 224-225)$.

${ }^{9}$ Hobbes ya había hecho este mismo reproche a la tradición filosófica: "ni Platón, ni ningún otro filósofo, hasta ahora ha puesto en orden y ha probado suficientemente, o de manera probable, todos los teoremas de doctrina moral" (Hobbes, 1999: XXXI, 311).
} 
(Essay, IV, XIX, §16). Aquí, en efecto, las Escrituras se presentan como una fuente objetiva, externa a la interpretación de la razón individual:

Allí donde la verdad que abrazamos se halla conforme a la palabra escrita de Dios, allí donde la acción que meditamos no se opone a los dictados de la recta razón y de las Sagradas Letras, podemos estar seguros de que no corremos ningún riesgo en considerarlas como inspiraciones divinas [ ]. Nada puede hacer eso, salvo la palabra escrita de Dios (que es exterior a nosotros) o aquella norma racional que nos es común con todos los otros hombres. Donde la razón o la Escritura autoricen expresamente alguna opinión o algún acto, podemos recibirlos como de autoridad divina (Essay, IV, XIX, \$16).

Este pasaje posee una ambigüedad manifiesta y significativa. En efecto, por un lado, en sentido literal, permitiría inferir que la Escritura constituye, por sí misma, una de las dos reglas infalibles en materia de "iluminaciones divinas" (Essay, IV, XIX, \$16). Esto significaría, considerando que la razón es la otra regla infalible, que las Escrituras por sí mismas son infalibles y constituyen un testimonio de "la palabra escrita de Dios (que es exterior a nosotros)" (Essay, IV, XIX, \$16). Ahora bien, por otro lado, el pasaje en el que se afirma que podemos estar seguros "allí donde la acción que meditamos no se opone a los dictados de la recta razón y de las Sagradas Letras", no hace sino desarmar la independencia de las Escrituras de la interpretación de la razón. Este es, por cierto, el tono general de Essay, el cual no es extraño al conjunto de su obra, ya que es recurrente esta apelación a la autoridad conjunta de la razón y de las Escrituras (véase TT, II, \$25, \$11, \$21; Essay, IV, XVIII, \$5-6). Aún siendo exteriores a nosotros, e infalibles por sí, no accedemos a las Escrituras sino a través de una interpretación de la razón individual. Aún cuando las Escrituras constituyen, por si mismas una fuente infalible, y dan cuenta de la palabra de Dios, veremos que la apelación a su autoridad requiere sin embargo de interpretación, justificación y pruebas por parte de la razón ${ }^{10}$.

En efecto, Locke comienza su análisis de la relación entre revelación y razón, afirmando que el testimonio de Dios "reclama el más alto grado de nuestro asentimiento, independientemente de que la cosa propuesta esté o no de acuerdo con la experiencia común y con el curso ordinario de las cosas” (Essay, IV, XVI, \$14). La palabra divina posee una autoridad por encima de la experiencia común, esto es, no requiere adecuarse a un criterio empírico de validación.

\footnotetext{
${ }^{10}$ Por otra parte, Locke deja en claro que, aún cuando se trata de un don divino, que lo vuelve a imagen y semejanza de Dios $(T T, \mathrm{I}, \$ 30$ ), la razón constituye una facultad intelectiva natural (Essay, IV, XVII, $\$ 1$; véase también I, IV \$22). En efecto, la razón es el medio de revelación natural y la vez es el medio a través del cual se interpretan las revelaciones no naturales: "la razón es la revelación natural, por donde el eterno Padre de la luz y manantial de todo conocimiento les comunica a los hombres esa porción de verdad que ha puesto al alcance de sus facultades naturales” (Essay, IV, XIX, \$4; véase también Aaron, 1965: 1 y ss.).
} 
La razón de esto es que se trata del testimonio de uno que no puede engañar y no puede ser engańado, y ése es el de Dios mismo. Es un testimonio que lleva consigo una seguridad más allá de la duda, una prueba más allá de toda excepción. Se le llama con un nombre peculiar, revelación, y al asentimiento que le concedemos se le dice $f e$, la cual determina de manera tan absoluta nuestra mente, y excluye de un modo tan perfecto toda indecisión, como puede hacerlo el conocimiento mismo (Essay, IV, XVI, \$14; véase, en el mismo sentido, la definición de fe en Essay, IV, XVIII, $\$ 2^{11}$ ).

El testimonio de Dios requiere el más alto grado de asentimiento, equivalente al conocimiento demostrativo que provee la razón (Ashcraft, 1969: 216). Ahora bien, la aceptación de un testimonio como palabra divina requiere estar seguro de su autoría (Ashcraft, 1969: 215). En efecto, al igual que lo hacía en $R$, habiendo dos vías de revelación, directa y tradicional, Locke va a reclamar para ambas la necesidad de pruebas $(R, 1977: 227-228)$. La prueba para la revelación, como ya hemos adelantado, no necesita adecuarse a la experiencia común ni ser racional-demostrativa, pero según Locke sí permite ofrecer corroboraciones.

Para el caso de la revelación directa, de la que una persona particular da testimonio, Locke exige que sea evaluada con el rigor de la sospecha cartesiana. En efecto, aún cuando la persona brinde testimonio honesto de su revelación y ésta efectivamente haya acontecido, puede tratarse de una revelación mentirosa producto de un genio maligno: "Porque si el vigor de la persuasión ha de ser la luz que nos sirva de guía, quisiera saber cómo hemos de distinguir entre los engaños de Satanás y las inspiraciones del Espíritu Santo” (Essay, IV, XIX, \$13).

Por otra parte, para el caso de la revelación por vía de la tradición, Locke exige pruebas de mayor envergadura. En efecto, todos aquellos que "reciban las verdades que han sido reveladas a otros hombres, las cuales por tradición escrita u oral les han sido comunicadas, tienen mucha más necesidad de la razón, y es ella la única que puede inducirnos a recibirlas" (Essay, IV, XVIII, \$6; véase también $\$ 8$; Essay, IV, XVII, \$24). Como se ve, la razón resulta siempre necesaria, y más aún en el caso de la revelación tradicional. La aceptación de la revelación requiere de una prueba clara a la razón, la cual, no pudiendo ser empírica ni demostrativa, debe poder dar cuenta de su procedencia divina. De otro modo:

“[...] siempre [quedará] pendiente esta objeción, a saber: que no sabríamos explicar cómo sea posible concebir que proceda de Dios, ese generoso Autor de nuestro ser, una cosa que, de ser recibida como verdadera, acarreará la ruina de todos los principios y fundamentos del conocimiento que Él mismo nos ha proporcionado; invalidará todas nuestras facultades; des-

\footnotetext{
11 "La fe, en cambio, es el asentimiento que otorgamos a cualquier proposición que no esté fundada en deducción racional, sino sobre el crédito del proponente, que viniera de Dios por alguna manera extraordinaria de comunicación. Esta manera de descubrir verdades a los hombres es lo que llamamos la revelación” (Essay, IV, XVIII, \$2).
} 
truirá completamente la parte más excelente de su obra, nuestro entendimiento, y colocará al hombre en una condición en que tendrá menos luz y menos guía que las bestias destinadas a perecer. Porque si la mente humana no puede jamás tener una evidencia más clara (y quizá no tan clara) acerca de que una cosa sea de revelación divina, como la que tiene acerca de los principios de su propia razón, jamás tendrá fundamento para abandonar la clara evidencia de su razón, y dejar su lugar a una proposición cuya revelación no goza de una mayor evidencia que la que les corresponde a aquellos principios" (Essay, IV, XVIII, \$5) ${ }^{12}$.

Locke es perfectamente consciente de los problemas que acarrea la aceptación de revelaciones para su teoría del conocimiento. Sabe que si no logra proveer un marco de corroboración, permitiría que cualquier afirmación subjetiva pase por una afirmación divina, por lo tanto verdadera e infalible. En este sentido, afirma que no puede aceptarse por palabra divina los deseos delirantes o el fanatismo de hombres perezosos: "nos exponemos a caer en todas las extravagancias del fanatismo y a incurrir en todos los errores de los falsos principios, puesto que tendremos fe y seguridad en lo que no es una revelación divina” (Essay, IV, XVI, \$14; véase también IV, XIX, \$5; Shapiro, 1968: 39). No puede aceptarse sin más el testimonio de quienes "sienten la mano de Dios agitándose en su interior" y "se persuaden de que la razón no tiene nada que hacer con lo que ven y sienten dentro de sí mismos" (Essay, IV, XIX, §8).

[...] el amor que tienen los hombres por lo que es extraordinario, y el gusto y gloria que hay en ser un inspirado y en situarse por encima de las comunes y naturales vías del conocimiento, halagan de tal manera la humana pereza, ignorancia y vanidad, que una vez engreídos en esta especie de revelación inmediata, en esta iluminación sin búsqueda, en esta certidumbre sin pruebas y sin examen, resulta muy difícil sacarlos de allí: la razón ya no es oponente para ellos; están por encima de ella (Essay, IV, XIX, \$8). Si la evidencia acerca de ser una revelación o acerca de su verdadero sentido se funda tan sólo en una prueba probable, nuestro asentimiento no puede elevarse más allá de la seguridad o de la desconfianza que justifique la mayor o menor probabilidad aparente de la prueba (Essay, IV, XVI, \$14).

De este modo, si la palabra divina requiere el más alto asentimiento, al igual que el conocimiento empírico-racional, no posee autonomía alguna respecto a la

\footnotetext{
12 Casi en los mismos términos, Hobbes había seńalado el problema de la apelación a una revelación contraria a la razón: "Se ha pensado también comúnmente que la fe y la santidad no se consiguen mediante el estudio y el uso de la razón, sino por infusión o inspiración sobrenatural. Si concedo esto, no veo por qué un hombre debe dar razón de su fe, o por qué cada cristiano no debería ser también un profeta, o por qué un hombre debería aceptar la ley de su país para guiarse en sus acciones, en vez de guiarse por su propia inspiración” [...] la pluma [en el original, "tongues", lenguas] de algunos indoctos teólogos que, reuniendo palabras de la Sagrada Escritura de un modo que no es compatible con la razón, hacen todo lo posible para que los hombres lleguen a pensar que la santidad y la razón natural no pueden darse juntas" (Hobbes, 1999, XXIX: 276)
} 
razón, pues el único modo de validar que se trata de una revelación es merced a pruebas aceptadas por la razón (Essay, IV, XVI, \$14). En este sentido específico, se comprende mejor (sin necesidad de aceptar su problemática formulación) la crítica de Strauss a la supuesta autonomía de la ley de naturaleza, como mandato divino, respecto a quien la interpreta (Strauss, 1992: 219-220, 216). En la misma dirección debe entenderse el comentario de Garotti respecto a la influencia de la crítica epistemológica de Essay sobre el concepto de ley de naturaleza:

La ley moral no es una 'forma' indiscernible, secreta, abierta a la visión 'entusiasta' a una revelación privilegiada. No está ni siquiera ya hecha, escrita en nosotros, indiferente al trabajo de la razón. El fundamento de la moral es la ley de Dios, pero el hombre no es un pasivo ejecutor, espectador de una revelación que no le pone en juego (Garotti, 1961: 156).

En efecto, no hay necesidad de apelar a la problemática interpretación de Strauss para establecer la sospecha sobre el carácter no sólo parcial, fanático y fantástico sino también interesado de la interpretación individual. Basta con citar al propio Locke: "[...] en todas las épocas la mayoría de los hombres prefieren su interés particular al interés público" (Essay, IV, XVI, $\$ 12$; véase también IV, $\mathrm{XX}, \$ 16$; Yolton, 1958: 495; Seliger, 1963: 345; 354; Gough, 1964: 18; sobre el individualismo lockeano, Singh, 1961: 115-116; Gough, 1964: 45-46, 43, 34; Hancey, 1976: 442; Gaela Esperanza, 2006: 89). Locke mismo subraya a lo largo de su obra cuán parcial puede ser la interpretación individual, especialmente en materia de fe (Essay, II, XXXIII \$18), lo cual se aplica especialmente a la interpretación de ley de naturaleza (TT, II, \$123). Al realizar su interpretación, el individuo puede alejarse de la razón no sólo por las limitadas capacidades del entendimiento humano (Essay, IV, XVI, \$4; véase también IV, III, \$1; I, I, \$4-6; Ashcraft, 1969: 209-210), sino también intencionadamente, al guiarse por el interés propio (TT, II, $\$ 124-128$, $\$ 184$ y especialmente $\$ 13$; véase también Aarsleff, 1969: 134).

"Así, Dios podría, por revelación, descubrirnos la verdad de cualquiera de las proposiciones de Euclides [ ]. En todas las cosas de esa clase, la revelación no hace falta, puesto que Dios nos ha dotado de medios naturales y más seguros para poder alcanzar el conocimiento de ellas [ ] nunca alcanzaría una certidumbre tan grande como el conocimiento que se tuviera de ella, basado en la comparación y medición de mis propias ideas acerca de dos ángulos rectos, y acerca de los tres ángulos de un triángulo. Lo mismo vale respecto a asuntos de hecho que pueden conocerse por los sentidos" (Essay, IV, XVIII, \$4). "Por lo tanto, respecto a nuestras ideas simples, que son la base y la única materia de todas nuestras nociones y conocimientos, es preciso que dependamos completamente de nuestra razón, quiero decir, de nuestra facultades naturales, y en modo alguno podemos recibir esas ideas, ni ninguna de ellas por vía de la revelación tradicional. Digo, revelación tradicional, para distinguirla de la revelación original. Por esta última, significo aquella primera impresión que Dios hace 
de una manera inmediata sobre la mente del hombre, y acerca de la cual no podemos fijar ningunos límites" (Essay, IV, XVIII, \$3; véase también IV, XVIII, \$5).

Es claro, por tanto, que Locke mismo propone una actitud escéptica, propia del empirismo racionalista que caracteriza a Essay, frente a toda pretensión de revelación. Hemos visto que sólo la razón puede aceptar las corroboraciones que se ofrezcan acerca de su procedencia divina. En este punto, Locke evita cuestionar la revelación en sí, pues de otro modo sería imposible la apelación a las Escrituras como fuente de autoridad moral, que ya hemos consignado aquí. Por lo tanto, sin dejar de afirmar la infalibilidad de las Escrituras, Locke exige para la revelación tradicional aún más corroboración que frente a la revelación directa (Essay, IV, XVIII, \$6), la cual, por su parte, hemos visto que resulta pasible de todo tipo de falsificaciones (Essay, IV, XIX, $\left.\$ 6^{13}\right)$. Estas pruebas o corroboraciones están dadas, en el caso de las Escrituras, por el anuncio de la llegada del Mesías, así como por los milagros de Jesús.

Para saber que cualquier revelación proviene de Dios, es necesario saber que el mensajero que la entrega es enviado por Dios, y eso no puede ser conocido sino por ciertas credenciales dadas a él [el mensajero] por Dios mismo" $\left(D M^{14}, 1824: 257\right)$. [...] debemos observar que hay una declaración triple del Mesías. 1. Por los milagros $(R, 1977: 89)$. 2. Otra manera de anunciar la venida del Mesías, era por frases y circunloquios que daban a entender o anunciaban su llegada ( $R, 1977: 91)$. 3. Por palabras sencillas y directas, declarando la doctrina del Mesías, demostrando que él era Jesús, como vemos que hicieron los apóstoles cuando iban por ahí predicando el Evangelio después de la resurrección de nuestro Salvador $(R, 1977: 92$; véase también $72,106-109,102,154-155,233-234)$. [...] es claro que creer en el Hijo es creer que Jesús era el Mesías, dando fe a los milagros que hizo y a la declaración que hizo de sí mismo ( $R, 1977: 72$; véase también 92; 106-109, 102, 154-155, 233-234; Gaela Esperanza, 2006: 79; Ashcraft, 1969: 216).

Como puede observarse, aquí que los milagros descritos en los Evangelios son tomados por Locke como corroboraciones empíricas de que Jesús recibe su revelación de Dios y no de un genio maligno. De este modo, Locke pretende satisfacer la necesidad de prueba y corroboración, para la aceptación de la autoría divina de una revelación que, por su naturaleza misma, no se corresponde con experiencia común (Essay, IV, XVI, \$14) ni puede recibir una prueba racional demostrativa. En esta misma dirección de satisfacer la necesidad de corroboración racional de la autoría divina de una revelación, se inscribe la apropiación que Locke realiza de la distinción escolástica según la cual las proposiciones pueden clasificarse entre las

\footnotetext{
13 "[...] cualesquiera que sean las acciones extravagantes que se vean inclinados a realizar, siempre se concluye que semejante impulso obedece a un llamado o mandato del cielo que es preciso obedecer” (Essay, IV, XIX, \$6).

14 A Discourse on Miracles en Locke, 1824, vol. VIII. Traducción del autor.
} 
que se hallan de acuerdo con razón, las que se ubican por encima de la razón y las que resultan contrarias a la razón. En efecto, la afirmación que diera cuenta de los milagros se halla por encima de la razón, es decir, no posee prueba demostrativa ni explicación por el uso natural de la razón.

Acordes con la razón son "aquellas proposiciones cuya verdad podemos descubrir al examinar y rastrear las ideas recibidas por sensación o por reflexión”, es decir, "por vía de una deducción natural” (Essay, IV, XVII, \$23; véase también IV, XVIII, $\$ 4)$. Por encima de la razón se consideran "aquellas proposiciones cuya verdad o probabilidad no podemos deducir de esos orígenes, por medio de la razón" (Essay, IV, XVII, \$23). Por último encontramos las afirmaciones contrarias a la razón, aquellas que resultan "incongruentes respecto nuestras ideas claras y distintas" (Essay, IV, XVII, \$23). "Así, la existencia de un dios es de acuerdo con la razón; la existencia de más de un dios, contrario a la razón, y la resurrección de los muertos, por encima de la razón (Essay, IV, XVII, \$23).

Esta triple distinción es fundamental para la separación que Locke pretende realizar entre las atribuciones falaces de revelación, con motivaciones subjetivas ya sea malintencionadas o meramente fantásticas, el uso natural de la razón, basado en el conocimiento empírico-racional, y la prueba que brindaría la autoría divina, corroborada por determinadas manifestaciones. Ahora bien, todo el planteo evidentemente carece de sustento, en la medida en que no se puede sostener al mismo tiempo la necesidad de pruebas para la razón (la cual evalúa toda evidencia en función de la coherencia lógica de las afirmaciones y en contraste con la experiencia) y, la mismo tiempo, tomar como palabra divina un testimonio en base a afirmaciones que se hallan "por encima de la razón" y contrarían la experiencia común. En efecto, ¿habría dos razones, una natural y otra sobrenatural? ¿Una que toma la demostración racional en base a la experiencia y otra que daría fe de un milagro por observación empírica pero sin el uso natural de la razón? ¿Cómo puede afirmarse al mismo tiempo que la razón es el único juez de toda revelación y, al mismo tiempo, que sus corroboraciones, sus pruebas, se halla por encima de la razón? En efecto, en los propios términos de Locke el hombre:

[...] jamás tendrá fundamento para abandonar la clara evidencia de su razón, y dejar su lugar a una proposición cuya revelación no goza de una mayor evidencia que la que les corresponde a aquellos principios (Essay, IV, XVIII, \$5). [...] la razón es el juez competente; y aunque la revelación, al estar de acuerdo, pueda confirmar sus decisiones, no puede, sin embargo, en tales casos, invalidar sus decretos. (Essay, IV, XVIII, \$6). Credo quia impossibile est, «lo creo porque es imposible», es una máxima que puede pasar en un hombre bueno como un arranque de celo; pero resultaría ser una regla muy mala para que los hombres se sirvieran de ella en la elección de sus opiniones o de su religión (Essay, IV, XVIII, \$11). 
En base a esta problematicidad entre exigencia de pruebas para la razón y aceptación de lo que se halla por encima de la razón, no es difícil advertir que existe una contradicción insalvable en la formulación lockeana (Ashcraft, 1969: 215, 223). De hecho, es Locke quien, una vez más, plantea objeciones que por elevación merman las pruebas por él mismo ofrecidas acerca de la veracidad de los Evangelios.

[...] yo no puedo comprender cómo, quienes sostienen que la revelación es el único objeto de la fe, puedan decir que es asunto de fe, y no de razón, creer que tal o cual proposición, que se encuentra en este o aquel libro, es de inspiración divina, a no ser que sepan por revelación que esa proposición, o todas las que se encuentran en ese libro, han sido comunicadas por una inspiración divina (Essay, IV, XVIII, \$6) ${ }^{15}$.

Locke establece aquí, en efecto, un criterio aún más escéptico: antes de aceptar lo que no es "acorde con la razón" es preciso poseer una revelación directa de que cada afirmación de un libro tiene a Dios por autor. De este modo, se evidencian los límites de la pretensión de Locke de conciliar un principio de autoridad basado en la palabra de Dios y la corroboración empírica coherente con la teoría del conocimiento de Essay (Lamprecht, 1918: 108; véase también; Ashcraft, 1969: 213-223). En efecto, es imposible para las Escrituras, como para cualquier otro testimonio de revelación, cumplir con el requisito de que cada una de sus afirmaciones sean corroboradas por una revelación directa para quien la recibe.

Podemos concluir, por tanto, que si bien las Escrituras constituyen una referencia central en la fundamentación moral lockeana, su apropiación resulta problemática a partir de la epistemología lockeana en general y, en términos más específicos, a partir de las exigencias de prueba y validación racional de las revelaciones afirmadas por vía tradicional.

\footnotetext{
15 Exactamente el mismo argumento podemos encontrarlo en el Leviatán: “¿cómo podrá un hombre que no ha tenido una revelación sobrenatural asegurarse de que el que declara esa ley lo ha hecho por revelación? Y ¿cómo podrá estar obligado a obedecer esa ley? En cuanto a la primera pregunta, es decir, la de cómo puede un hombre asegurarse de la revelación recibida por otro, sin que él mismo haya sido depositario de una revelación particular, la respuesta es que le resultará imposible asegurarse. [...] Los milagros son cosas maravillosas; pero lo que es maravillosos para uno, puede no serlo para otro. La santidad puede ser meramente fingida; y las felicidades visibles de este mundo, son muy frecuentemente obra de Dios, realizada mediante causas naturales y ordinarias. Por tanto, ningún hombre puede saber infaliblemente, por razón natural, si otro ha tenido una revelación sobrenatural de la voluntad de Dios; tendrá sólo una creencia; y, según los signos de dicha revelación sean mayores o menores, la creencia será más firme o más débil” (Hobbes, 1999, XXVI: 246-247).
} 


\section{REFERENCIAS Bibliográficas}

\section{Primaria}

Locke, J. 1824: Works of John Locke in Nine Volumes. Londres: Rivington.

- 1965: Enssays on the law of nature. The latin text with a traslation, introduction and notes, together with transcripts of Locke's shorthand in his journal of 1676 (ed. W. von Leyden). Oxford: Oxford University Press.

- 1967: Two Tracts on Government (tr. P. Abrams). Cambridge: Cambridge University Press.

— 1977: La racionalidad del cristianismo (tr. Leandro González Puertas). Madrid: Ediciones Paulinas.

- 1978: The correspondence of John Locke (ed. E. S. de Beer). Volume IV. Oxford: Oxford University Press.

- 1991: Examen de la opinión del padre Malebranche de ver todas las cosas en Dios. En Obras varias y correspondencia de (y sobre) John Locke (tr. José Antonio Robles y Carmen Silva). México: Universidad Autónoma Metropolitana, pp. 35-81.

- 1999: "Carta sobre la tolerancia" en Escritos sobre la tolerancia (tr. L. Prieto Sanchís y J. Betegón Carrillo). Madrid: Centro de estudios políticos y constitucionales, pp. 107-151.

- 2004: Two Treatises of Government (tr. Peter Laslett). Cambridge: Cambridge University Press.

- 2007: La Ley de la Naturaleza (tr. Carlos Mellizo). Madrid: Tecnos.

— 2011: "De la Ética en general" En Ensayo sobre la tolerancia y otros escritos sobre ética y obediencia civil (tr. Blanca Rodríguez López y Diego A. Fernández Peychaux). Madrid: Minerva, pp. 155-165.

\section{Secundaria}

Aaron, R. 1965: John Locke. London: Oxford University Press.

Aarsleff, H. 1969: "The state of nature and the nature of man in Locke". En Yolton, John W. (ed.). John Locke: Problems and Perspectives. Cambridge: Cambridge University Press, pp. 99-136.

Ashcraft, R. 1968: "Locke's State of Nature. Historical fact or Moral Fiction?". The American Political Science Review. Vol. LXII, N 3, pp. 898-915. 
— 1969: "Faith and knowledge in Locke's philosophy". En Yolton. John W. (ed.). 1969: John Locke: Problems and Perspectives. Cambridge: Cambridge University Press, pp. 194-223.

Chumbita, J. S. 2011: "El desplazamiento en la teoría de la propiedad de John Locke: del criterio de necesidad a la teoría del valor para justificar la colonización inglesa en América”. Cuyo: Anuario de filosofía Argentina y Americana. Vol. 28, pp. 93-120.

- 2013a: "Un análisis de las nociones de abundancia y esclavitud para reinterpretar el carácter universal de la teoría de la apropiación de John Locke”. Las torres de Lucca. $\mathrm{N}^{\circ}$ 2. Enero-junio, pp. 69-83.

— 2013b: "La caridad como administración de la pobreza". Identidades. Revista del Instituto de Estudios Sociales y Políticos de la Patagonia. $N^{\circ}$ 4. Junio, pp. $1-21$.

- 2013c: "Apropiación privada de la tierra y derechos políticos en la obra de John Locke". Ingenium. Revista de historia del pensamiento moderno. $\mathrm{N}^{\circ} 7$, pp. 193-210.

— 2014a: "Teología política, libertad natural, paz relativa y secularización en el estado de naturaleza descrito por John Locke". Bajo palabra. № 9. Septiembre (en prensa).

- 2014b: "La resistencia social como configuración del pueblo según John Locke”. Revista SAAP. Vol. 8. N 1 (en prensa).

— 2014c: "Actores sociales y económicos en las propuestas jurídicas y normativas de John Locke". Anales del Seminario de Historia de la Filosofía. Vol. 31. $\mathrm{N}^{\circ} 1$ (en prensa).

DunN, J. 1969: The political thought of John Locke. An historical account of the argument of the "Two Treatises of gobernment". Cambridge: Cambridge University Presss.

Filmer, Sir R. 1966: Patriarcha en La polémica Filmer-Locke sobre la obediencia política. Madrid: Instituto de estudios políticos.

Gaela Esperanza, J. 2006: John Locke and the Natural Law. Yesterday and today: a critical analysis. Extracto de Tesis Doctoral. Pamplona. Facultad Eclesiástica de Filosofía. Universidad de Navarra.

Gough, J. W. 1964: John Locke’s Political Philosophy. Oxford: Oxford University Press. 
HaLl, R. 1981: John Locke and Natural Human Rights: an Inconsistency between his metaphysical/epistemological positions and his moral/political theories. Michigan: University Microfilms International.

Hancey, J. O. 1976: "John Locke and the Law of Nature". Political Theory. Vol. 4. $\mathrm{N}^{\circ}$ 4. Nov., pp. 439-454.

Hоввеs, T. 1999: Leviatán (tr. Mellizo). Buenos Aires: Alianza.

Lamprecht, S. P. 1918: The moral and Political Philosophy of John Locke. New York: Columbia University Press.

Seliger, M. 1963: "Locke's Natural Law and the Foundation of Politics". Journal of the History of Ideas. Vol. 24. No. 3, pp. 337-354.

Shapiro, B. J. 1968: "Latitudinarianism and Science in Seventheenth-Century England”. Past \& Present. N ${ }^{\circ}$ 40. Jul., pp. 16-41.

Singh, R. 1961: "John Locke and the Theory of Natural Law". Political Studies. Vol. IX. N'2, pp. 105-118.

Simmons, A. 1992: The lockean theory of rights. Princenton: Princenton University Press.

Strauss, L. 1992: Natural Right and History. Chicago: Chicago University Press.

Yolton, J. W. 1958: "Locke on the Law of Nature", The philosophical Review, vol. 67, N 4. Oct., pp. 477-498. 